\title{
Formulation and Evaluation of Orodispersible Tablets of Zolmitriptan
}

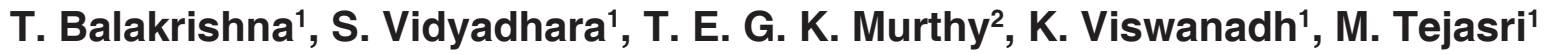 \\ ${ }^{1}$ Departent of Pharmaceutics, Chebrolu Hanumaiah Institute of Pharmaceutical Sciences, Guntur, \\ Andhra Pradesh, India, ${ }^{2}$ Bapatla College of Pharmacy, Bapatla, Andhra Pradesh, India
}

\begin{abstract}
Aim: The aim of this study is to formulate and evaluate zolmitriptan orodispersible tablets using novel excipients. Zolmitriptan is an antimigraine drug used in the treatment of migraine. Materials and Methods: In the present investigation, an attempt has been made to enhance the solubility and dissolution rate of zolmitriptan by formulating it as orodispersible tablets were compressed as tablets using superdisintegrants such as croscarmellose sodium and crospovidone. Results and Discussion: Rapid release of zolmitriptan from orodispersible tablets was observed which was influenced by the concentration of superdisintegrants. Among the various tablet formulations prepared with superdisintegrants croscarmellose, $40 \%$ showed rapid drug release. The release was found to follow the first order kinetics. The dissolution rate of tablet formulations was found to release the drug at a faster rate than the tablets prepared with plain drug. The drug excipients compatibility was confirmed by Fourier transform infrared and X-ray diffraction studies. No significant changes were observed from these studies.
\end{abstract}

Key words: Croscarmellose sodium, crospovidone, orodispersible tablets, stevia, zolmitriptan

\section{INTRODUCTION}

$\mathrm{T}$ There has been an enhanced demand for more patient-friendly and compliant dosage forms in the present day market. As a result, the demand for developing new technologies has been increasing annually. For most therapeutic agents used to produce systemic effects, the oral route still represents the preferred way of administration, due to its several advantages and high patient compliance compared to many other routes. Drug dissolution and absorption, as well as the onset of clinical effect and drug bioavailability, may be significantly greater than those observed from conventional dosage forms. ${ }^{[1]}$ For the past few decades, researchers have been developing intraoral delivery systems that can produce desirable drug exposure for optimum therapeutic effect. As a result as evident from the abundance of scientific and patent literature over the last 20 years, nontraditional oral dosage forms (e.g., buccal, sublingual, etc.,) have been or are being developed with emphasis on pre-gastric absorption by the various tissues of the oral cavity with the intention to avoid first-pass and gut wall metabolism, to enhance bioavailability, or improve convenience of dosing. The target sites for local drug delivery in the oral cavity include the following: Buccal, sublingual, periodontal, periodontal pocket, peribuccal, perilingual, tongue (i.e., lingual), and gum (i.e., gingival). ${ }^{[2]}$

Orodispersible tablets are also called as ODTs, quick disintegrating tablets, mouth dissolving tablets, fast disintegrating tablets, fast dissolving tablets, rapid dissolving tablets, porous tablets, and rapid melts. However, of all the above terms, United States pharmacopoeia (USP) approved these dosage forms as ODTs. The European Pharmacopoeia has used the term ODT for tablets that disperse readily within $3 \mathrm{~min}$ in the mouth before swallowing. ${ }^{[3]}$ The United States Food and Drug Administration defined ODT as "A solid dosage form containing a medicinal substance or active ingredient which disintegrates rapidly usually within a matter of seconds when placed on the tongue." The disintegration time for ODTs generally ranges from several seconds to about a minute. ${ }^{[4-6]}$ ODTs are intended to disintegrate fast

\section{Address for correspondence: \\ T. Balakrishna, Chebrolu Hanumaiah Institute of Pharmaceutical Sciences, Chandarmoulipuram, Chowdavaram, Guntur - 522 019, Andhra Pradesh, India. E-mail: balakrishnathalamanchi@gmail.com}

Received: 20-09-2016

Revised: 09-10-2016

Accepted: 18-10-2016 
in the mouth to provide dispersion before being swallowed where the active ingredient is intended for gastrointestinal delivery and/or absorption. ${ }^{[7,8]}$ There is an intense search for low-calorie sweeteners and high potency to provide an alternative to sugar for its use in food and drugs. ${ }^{[9]} \mathrm{Stevia}^{\left[{ }^{[10]}\right.}$ is a natural non-calorie sweetener obtained and extracted from the leaves of the plant species Stevia rebaudiana. The main active components of stevia are steviol glycosides (mainly stevioside and rebaudioside), which have up to 150 times the sweetness of sugar, are heat-stable, pH-stable, and not fermentable. These steviosides have a negligible effect on blood glucose, which makes stevia attractive to people on carbohydrate-controlled diets. Stevia's taste has a slower onset and longer duration than that of sugar, and some of its extracts may have a bitter or licorice-like aftertaste at high concentrations.

A migraine is a severe, painful headache that is accompanied by sensory warning signs such as flashes of light, blind spots, tingling in the arms and legs, nausea, vomiting, and increased sensitivity to light and sound. The excruciating pain that migraines bring can last for hours or even days. Migraine treatment and prevention focus on avoiding triggers, controlling symptoms and taking medicines. Over-the-counter medications such as naproxen, ibuprofen, acetaminophen and other analgesics like aspirin with caffeine are often the first abortive therapies to eliminate a headache or substantially reduce pain. Zolmitriptan undergoes highly hepatic first pass metabolism and to solve the problems of hepatic first pass metabolism prepare sublingual tablets. ${ }^{[11,12]}$

Zolmitriptan is a selective 5-hydroxytryptamine receptor subtype agonist indicated for the acute treatment of migraine attacks with or without aura in adults. Zolmitriptan is not intended for the prophylactic therapy of migraine or use in the management of hemiplegic or basilar migraine. Zolmitriptan is an agonist for a vascular 5-hydroxytryptamine receptor subtype (probably a member of the 5-HT ID family) having only a weak affinity for 5-HT1A, 5-HT5A, and 5-HT7 receptors and no significant affinity or pharmacological activity at 5-HT2, 5-HT3 or 5-HT4 receptor subtypes or at alpha-1, alpha-2, or beta-adrenergic, dopamine-1, dopamine-2; muscarinic, or benzodiazepine receptors. Zolmitriptan binds with high affinity to human 5-HT111 and 5-HT ID receptors leading to cranial blood vessel constriction. ${ }^{[13-16]}$

In present investigation, an attempt has been made to enhance the solubility and dissolution rate of zolmitriptan by formulating it as orodispersable tablets employing superdisintegrants.

\section{MATERIALS AND METHODS}

Zolmitriptan A gift sample from Apotex Pharma Ltd., Bengaluru. Croscarmellose sodium (CCS) and crospovidone (CP), KollidonVA64, were commercially produced from Yarrow Chem, Ltd., Mumbai. Magnesium stearate and mannitol were commercially produced from S.D. Fine Chem, Ltd., Mumbai.

\section{Saturated solubility studies}

Saturated solubility studies of zolmitriptan were performed in different dissolution media. An excess amount of lansoprazole was weighed and transferred into different conical flasks containing $10 \mathrm{ml}$ of different dissolution media, that is, water, $6.8 \mathrm{pH}, 7.2 \mathrm{pH}$ phosphate buffer, $1.2 \mathrm{pH}$ and were closed appropriately. All conical flasks were placed in the REMI incubator shaker. The shaker was allowed to operate at $50 \mathrm{rpm}$ at $37^{\circ} \mathrm{C} \pm 1{ }^{\circ} \mathrm{C}$ for $24 \mathrm{~h}$. Then, the conical flasks were removed from the incubator shaker, and the samples were filtered by using Whatman filter paper. The clear solution obtained by filtration was suitably diluted with appropriate dissolution media and the absorbance values were noted at $225 \mathrm{~nm}$ by using corresponding dissolution media as blank solutions.

\section{Preparation of zolmitriptan orodispersible tablets by direct compression}

Orodispersible tablets of zolmitriptan were prepared by direct compression with increasing the concentration ratios of croscarmellose and as a superdisintegrants were selected for the preparation of tablets. The ingredients were blended with super disintegrants such as CCS and CP, magnesium stearate and talc as lubricant and glidant. The powder blend was directly compressed into tablets using 10 station mini presses (ELITE). The compositions of various tablet formulations are given in Table 1.

\section{Evaluation of physical parameters for zolmitriptan orodispersible tablets}

The compressed tablets were further evaluated for their physical parameters such as weight uniformity, hardness, friability, and drug content.

\section{Dissolution studies on zolmitriptan orodispersible tablets}

Dissolution rate studies of zolmitriptan tablets were performed in USP Apparatus Type II (paddle) as per the procedure described earlier. Based on the data obtained from the dissolution studies various parameters such as $\mathrm{T}_{50}$, $\mathrm{DE} 30 \%$ zero order, and first order release rate constants were estimated. The dissolution parameters such as $\mathrm{T}_{50}$, and DE $30 \%$ were measured directly from the dissolution profile curves as shown in Figure 1a and $\mathrm{b}$.

\section{Characterization of orodispersible tablets}

Among the various tablet formulation prepared by using CCS and CP CCS showed rapid drug release when compared 


\begin{tabular}{lcccccccccccc}
\multicolumn{10}{c}{ Table 1: Compositions of various zolmitriptan orodispersible tablets } \\
\cline { 2 - 15 } Ingredients (mg/tab) & F1 & F2 & F3 & F4 & F5 & F6 & F7 & F8 & F9 & F10 & F11 & F12 \\
\hline & 5 & 5 & 5 & 5 & 5 & 5 & 5 & 5 & 5 & 5 & 5 & 5 \\
Zolmitriptan & 15 & 20 & 25 & 30 & 35 & 40 & - & - & - & - & - & - \\
CCS (mg) & - & - & - & - & - & - & 15 & 20 & 25 & 30 & 35 & 40 \\
Crospovidone (mg) & 137 & 132 & 127 & 122 & 117 & 112 & 137 & 132 & 127 & 122 & 117 & 112 \\
MCC (mg) & 40 & 40 & 40 & 40 & 40 & 40 & 40 & 40 & 40 & 40 & 40 & 40 \\
Mannitol & 1.5 & 1.5 & 1.5 & 1.5 & 1.5 & 1.5 & 1.5 & 1.5 & 1.5 & 1.5 & 1.5 & 1.5 \\
Stevia powder (mg) & 1.5 & 1.5 & 1.5 & 1.5 & 1.5 & 1.5 & 1.5 & 1.5 & 1.5 & 1.5 & 1.5 & 1.5 \\
Magnesium sterate (mg) & 200 & 200 & 200 & 200 & 200 & 200 & 200 & 200 & 200 & 200 & 200 & 200 \\
Total weight of tablets (mg) & 200
\end{tabular}

CCS: Croscarmellose sodium, MCC: Microcrystalline cellulose

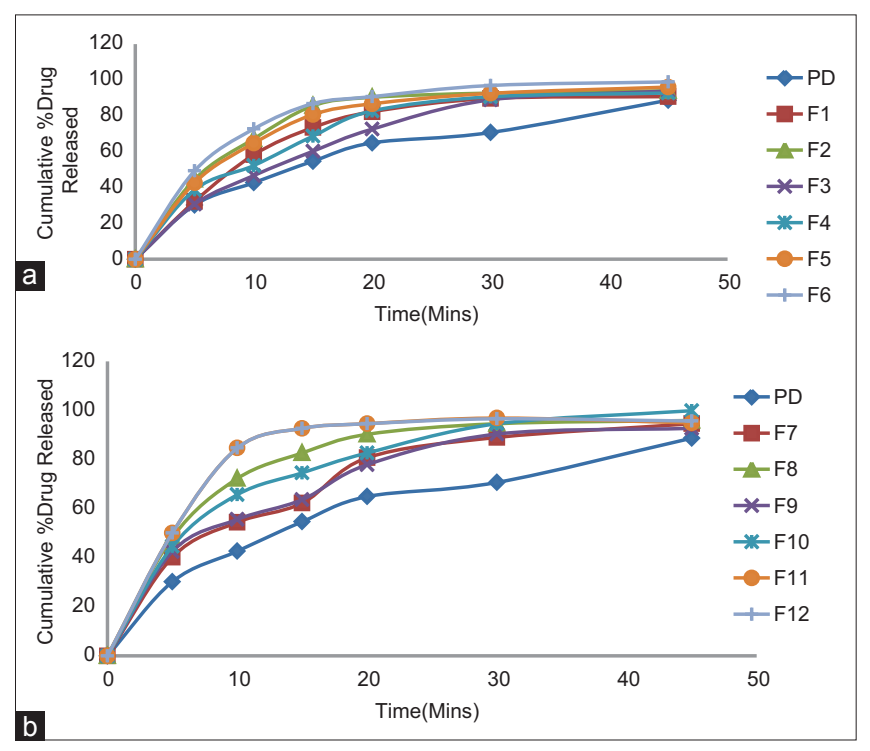

Figure 1: $(a$ and b) Drug release profiles of zolmitriptan orodispersible tablets

to $\mathrm{CP}$ and was further evaluated for the drug excipient compatibility by Fourier transform infrared (FTIR), X-ray diffraction (XRD) studies.

\section{Fourier transforms infrared spectroscopy study}

The FTIR spectra of zolmitriptan, superdisintegrants, and formulations were obtained using brucker FTIR spectrophotometer to study the interaction between drug and excipients in orodispersible tablets. The samples were prepared in $\mathrm{KBr}$ discs (2 mg sample in $200 \mathrm{mg}$ $\mathrm{KBr}$ ) and the sampling range was $400-4000 \mathrm{~cm}^{-1}$ and the resolution was $4 \mathrm{~cm}^{-1}$. The FTIR spectra are shown in Figure $2 \mathrm{a}$ and $\mathrm{b}$.

\section{X-ray diffraction study}

Powder XRD (PXRD) patterns were tracted employing X-ray Diffractometer Burker AXS, DH Advances, Germany for all the samples using Ni filetr, $\mathrm{CuK}(\dot{\alpha})$ radiation, a voltage of $\mathrm{kV}$, a current of $20 \mathrm{~mA}$ and receiving slit of 0.2 . The samples were analyzed over $2 \theta$ range of $5^{\circ}$ to $60^{\circ}$, with scan step size of $0.020^{\circ}(2 \theta)$ and scan step time of $1 \mathrm{~s}$. The XRD spectra are shown in Figure $3 a$ and $b$.

\section{RESULTS AND DISCUSSION}

Saturated solubility studies revealed that zolmitriptan show maximum solubility in $6.8 \mathrm{pH}$ phosphate buffer medium than the other medium used. The drug concentration was measured at an absorption maximum of $225 \mathrm{~nm}$ using ultraviolet spectrophotometer (ELICO SL120) for all dissolution medium. The compositions of various tablets prepared were shown in Table 1. All the orodispersible tablets were compressed under identical conditions to avoid processing variables. The physical parameters such as weight uniformity, hardness, friability, and drug content, were evaluated for all the tablets prepared. The physical parameters evaluated were highly uninformed and all tablets were found to be within the I.P. specified limits. The weight uniformity values were in the range of $198 \pm 3.0$ to $200 \pm 10 \mathrm{mg}$, hardness was found to be $3.5 \pm 0.4 \mathrm{~kg} / \mathrm{cm}^{2}$, friability values were in the range $0.1-0.8 \%$ and drug content values were in the range of $29.98 \pm 0.2 \mathrm{mg} /$ tablet for the zolmitriptan ODT formulations. The dissolution studies on zolmitriptan marketed tablet, and all the tablet formulations were performed by using $6.8 \mathrm{pH}$ phosphate buffer using paddle method. The dissolution rate of the tablet formulations was found to be rapid when compared to marketed tablet of zolmitriptan (zolmig $5 \mathrm{mg}$,). Among the tablets prepared tablets with the CCS as superdisintegrants in the concentration of $40 \%$ tend to exhibit rapid dissolution than all the formulations. The rate of rapid drug release is in the order of CCS $>\mathrm{CP}$ in the tablet formulations for superdisintegrants. Among the various tablet formulations F6 shows rapid drug release (up to 99.8\%) when compared to marketed formulation $(84.89 \%)$. This can be attributed improved wettability and dispersibility as well as increased amorphous fraction of drug. It was also found that as the concentration of superdisintegrants increases, 
the tablets undergo rapid dissolution and drug release. This may be due to rapid intake of water by superdisintegrants, which leads to the faster dissolution of the tablets and showed the improved dissolution profiles of poorly soluble zolmitriptan. The in vitro dissolution parameters were given in Table 2.
The formulations, which showed good in vitro performance, were subjected to accelerated stability studies. The formulation F6 was subjected to accelerated stability studies. It was also observed that there was no significant change in drug release from the tablet formulations. Thus, the drug release characteristics of zolmitriptan ODTs designed were found to be stable.

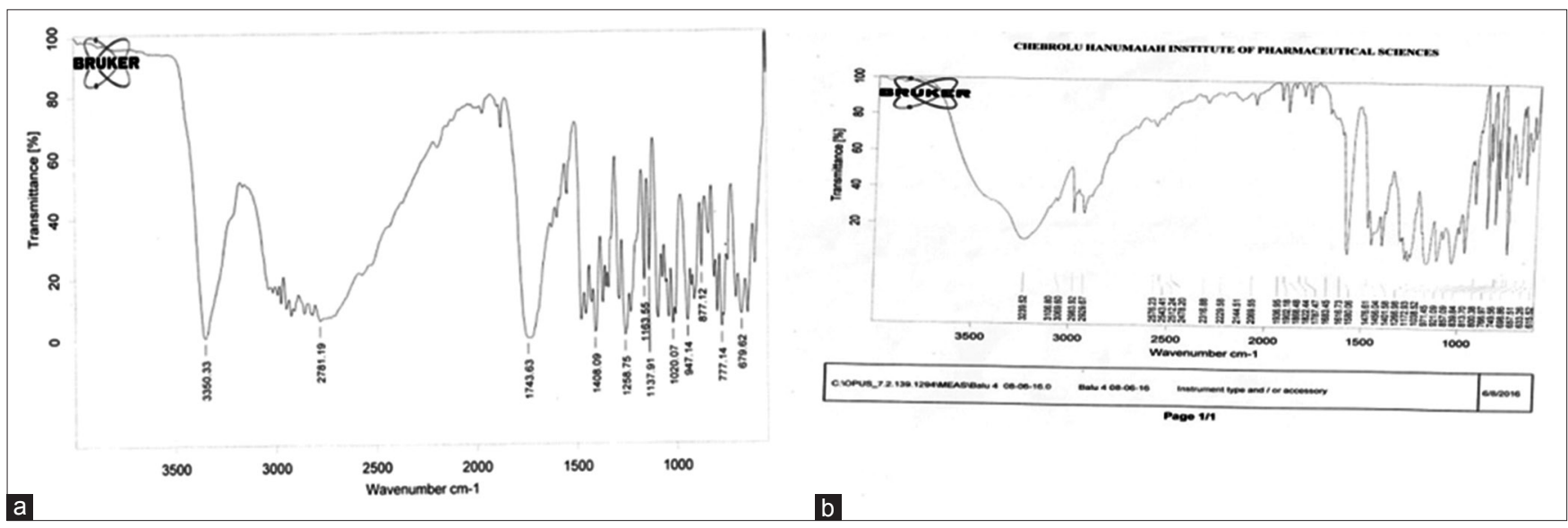

Figure 2: Fourier transform infrared spectra of zolmitriptan (a) pure drug (b) F6

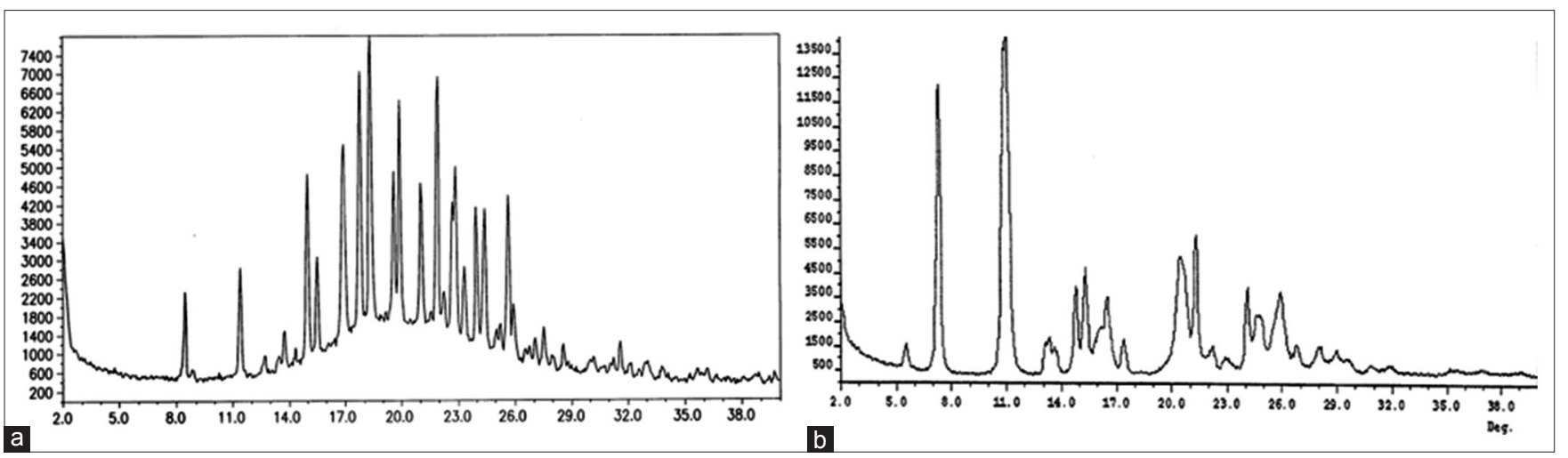

Figure 3: ( $a$ and b) X-ray diffraction studies of zolmitriptan pure drug and F6

\begin{tabular}{|c|c|c|c|c|c|c|}
\hline \multirow[t]{2}{*}{ Tablet formulations } & \multirow[t]{2}{*}{$\mathrm{T}_{50}(\mathrm{~min})$} & \multirow[t]{2}{*}{ DE30\% } & \multicolumn{2}{|c|}{ Zero order } & \multicolumn{2}{|c|}{ First order } \\
\hline & & & $R^{2}$ & $\mathrm{~K}(\mathrm{mg} / \mathrm{min})$ & $R^{2}$ & $K\left(\min ^{-1}\right)$ \\
\hline $\mathrm{F} 1$ & 10 & 60.5 & 0.382 & 0.929 & 0.80 & 0.010 \\
\hline $\mathrm{F} 2$ & 8 & 43.33 & 0.493 & 0.781 & 0.93 & 0.015 \\
\hline F3 & 11 & 53.33 & 0.493 & 1.006 & 1.08 & 0.027 \\
\hline $\mathrm{F} 4$ & 10 & 56.66 & 0.482 & 0.643 & 0.93 & 0.027 \\
\hline F5 & 7 & 36.66 & 0.507 & 0.697 & 1.00 & 0.021 \\
\hline F6 & 5 & 28.75 & 0.702 & 1.243 & 0.92 & 0.021 \\
\hline F7 & 8 & 32.98 & 0.612 & 1.446 & 0.99 & 0.029 \\
\hline F8 & 6 & 25.5 & 0.382 & 0.929 & 0.80 & 0.010 \\
\hline F9 & 7 & 33.33 & 0.493 & 0.781 & 0.93 & 0.015 \\
\hline F10 & 5 & 27.33 & 0.493 & 1.006 & 1.08 & 0.027 \\
\hline $\mathrm{F} 11$ & 6 & 30.66 & 0.482 & 0.643 & 0.93 & 0.027 \\
\hline F12 & 6 & 31.66 & 0.507 & 0.697 & 1.00 & 0.021 \\
\hline
\end{tabular}




\section{CONCLUSION}

The present study has shown that it is possible to increase the dissolution rate of poorly soluble drug zolmitriptan by preparing it as orodispersible tablets using various superdisintegrants shows the rapid dissolution and drug release when compared with marketed tablets. Based on the study, it may be concluded that zolmitriptan tablets prepared using CCS as superdisintegrant was found to be ideal for rapid dissolution rate, which, in turn, increases the bioavailability.

\section{ACKNOWLEDGMENTS}

The authors express their gratitude to Apotex pharma Ltd., Bangalore for providing the gift samples. The authors are thankful to the management of Chebrolu Hanumaiah Institute of Pharmaceutical Sciences, Guntur for providing the facilities to carry out the research work.

\section{REFERENCES}

1. Hirani JJ, Rathod DA, Vadalia KR. Orally disintegrating tablets: A review. Trop J Pharm Res 2009;8:161-72.

2. William R, Pfister WR, Gosh TK. Intra-oral delivery systems: An overview, current status and future trends. In: Ghosh TK, Pfister WR, editors. Drug Delivery to the Oral Cavity. Landon, New York, Singapore: Taylor and Francis Group; 2005. p. 2.

3. Fu Y, Yang S, Jeong SH, Kimura S, Park K. Orally fast disintegrating tablets: Developments, technologies, taste-masking and clinical studies. Crit Rev Ther Drug Carrier Syst 2004;21:433-76.

4. Brown D. Orally disintegrating tablets - taste over speed. Drug Deliv Technol 2003;3:58-61.

5. Nagar P, Singh K, Chauhan I, Verma M, Yasir M,
Khan A, et al. Orally disintegrating tablets: Formulation, preparation techniques and evaluation. J Appl Pharm Sci, 2011;1:35-45.

6. Kumar SV, Gavaskar B, Sharan G, Rao YM. Overview on fast dissolving films. Int $\mathrm{J}$ Pharm Pharm Sci 2010;2:29-33.

7. Committee for Medicinal Products for Human Use, European Medicines Agency EMEA Reflection Paper: Formulation of Choice for the Pediatric Population; 2006.

8. Council of Europe. European Pharmacopoeia. $8^{\text {th }}$ ed. Strasbourg, France: Council of Europe; 2014.

9. Crammer B, Ikan R. Properties of synthesis of sweetening agents. Chem Soc Rev 1977;6:431-65.

10. British and World English. 07 February; 2013. Available from: http://www.oxforddictionaries.com. [Last retrieved on $13 \mathrm{Feb} 2013]$.

11. Desu P, Sahu M. Formulation and evaluation of fast dissolving films of zolmitriptan. Int Res J Pharm 2012;3:373-6.

12. Rao NG, Munde MR. Formulation and in-vitro evaluation of mucoadhesive buccal films of zolmitriptan. J Pharm Res 2011;4:2682-5.

13. Galey WR, Lonsdale HK, Nacht S. The in vitro permeability of skin and buccal mucosa to selected drugs and tritiated water. J Invest Dermatol 1976;67:713-7.

14. Walton RP. Absorption of drugs through the oral mucosa. III fat-water solubility coefficient of alkaloids. Proc Soc Exp Bio Med 1935;32:1488.

15. Suresh B, Halloran D, James L. Quick dissolving films: A novel approach to drug delivery. Drug Dev Technol 2006;3:1-7.

16. Sweetman SC. Martindlae: The Complete Drug Reference. $36^{\text {th }}$ ed. London, England, UK: Pharmaceutical Press; 2009. p. 1214.

Source of Support: Nil. Conflict of Interest: None declared. 